\section{PAGES has a QUEEN}

The European climate has been subject to rapid and dramatic changes during the recent geological past, mainly because of the instability and variability of the regional extension of the temperate climatic zones into very high northern latitudes, in particular over northwestern Europe and the adjacent ocean basin. Because of the difficulties in accessibility the Arctic Ocean, the Eurasian shelf seas and the high latitudes of northern Europe and northern Asia have remained behind in developing an understanding of how they responded to the Late Quaternary climatic changes and how they influenced the climate over northwestern Europe.

Over the past years, numerous bilateral projects have developed between research institutions in western European countries, North America and Russia in an effort to solve various aspects of the paleoclimatic history of northernmost Eurasia and the adjacent Arctic. The program "Quaternary Environments of the Eurasian North (QUEEN)" is sponsored by the European Science Foundation and tries to promote the exchange of information between the many ongoing projects in northern Eurasia and the adjacent Arctic Ocean which try to reconstruct the regional paleoclimate during the last two climatic cycles. QUEEN attempts to correlate well-established and well-dated marine and terrestrial records of the Late Quaternary paleoenvironmental history of the northern and eastern vast regions which were partly covered by one of the large Arctic ice sheets. Adjacent to the Eurasian ice sheets, a periglacial environment developed which was the habitat of mammoth and other now extinct megafauna. The mammoth has been chosen to dominate the QUEEN logo.
While the western European record of this history can be considered relatively well-known, the northern, southern, and eastern extension of these ice sheets during the last glacial maximum and the regional coherence of the individual ice domes is still relatively poorly understood. QUEEN attempts to synthesize the new knowledge gained through the many ongoing efforts in the area of interest and to stimulate new investigations in areas which may hold clues for a better understanding of this history. QUEEN recently published the first compilation of the Eurasian ice sheet distribution during the last glacial maximum, and there is no question that it never extended further to the east than the Taymyr Peninsula and the Central Siberian Uplands. This map (see figure) has been published in the first international volume describing results of the QUEEN project (BOREAS, vol. 28, No 1,1999 ) in a summary paper by Svendsen et al. The third QUEEN workshop was conducted in April 1999 in the Hardangerfjord/Norway. The program of the workshop, the list of participants and the abstracts of the sci-

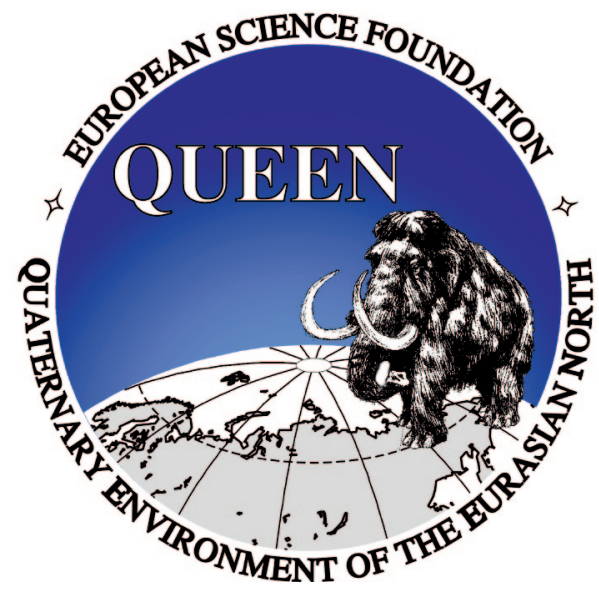

entific presentation, as well as the membership of the QUEEN Steering Committee are accessible via world wide web: www.geomar.de/ hbauch/king/ html/queen.html.

\section{Jörn Thiede and Henning Bauch \\ GEOMAR Forschungszentrum für Marine Geowissen- schaften, CAU Kiel, Germany \\ jthiede@geomar.de \\ hbauch@geomar.de}

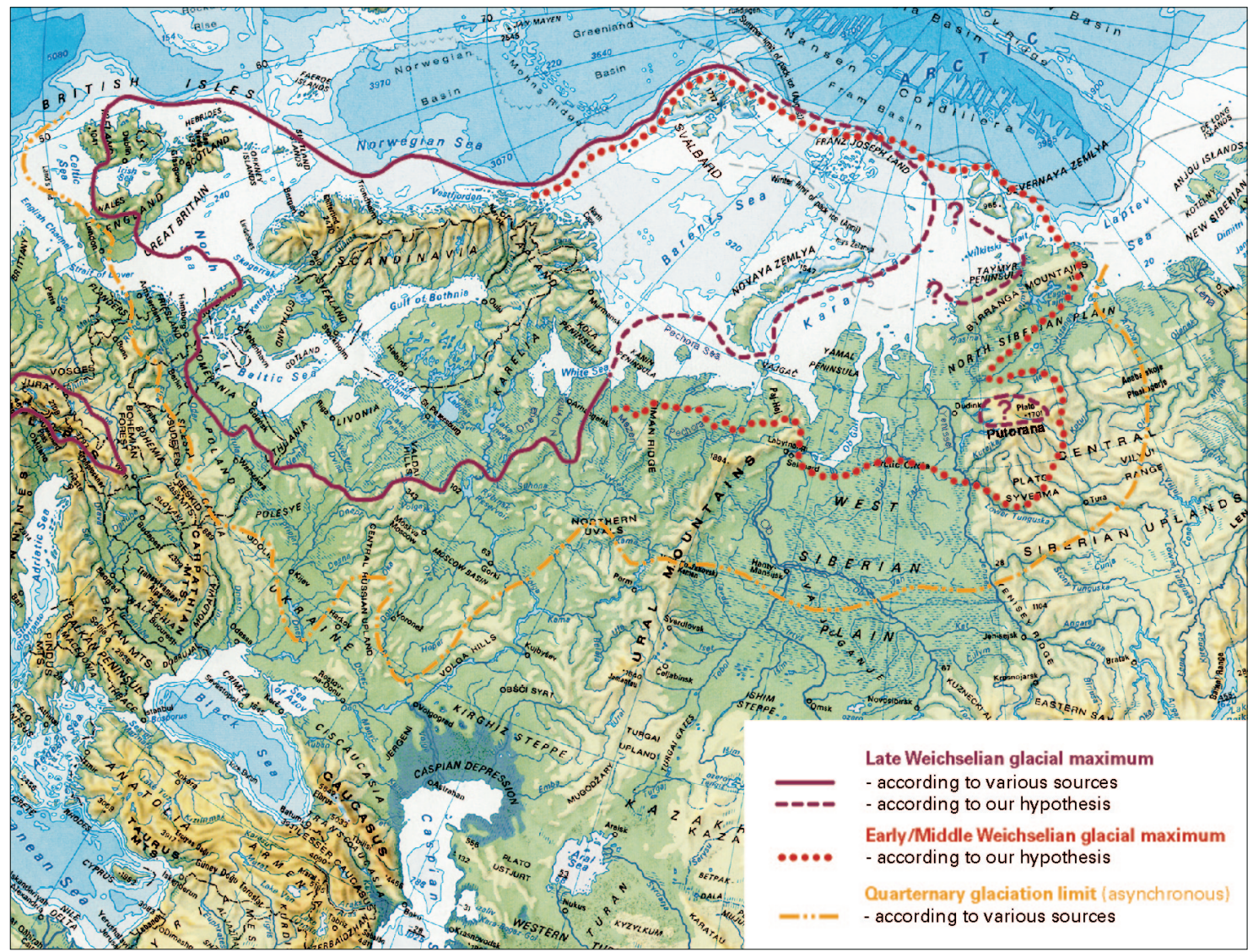

Reconstructions of ice-sheet extent during the last glacial maximum as published by Svendsen et al. in 1999. 